Everyday Life Information Needs of Adolescents

Kimberly Hirsh

The University of North Carolina at Chapel Hill, Chapel Hill, NC 


\section{Everyday Life Information Needs of Adolescents}

In its National Research Agenda, the Young Adult Library Services Association identifies the "Information Seeking Behaviors and Needs of Young Adults" as a key priority for future research (2011, p. 11). Young adults seek information not only in their role as students, but also to address "real life" or "daily life" issues (Bernier, 2007). To support young adults as they seek information, librarians must recognize the ways that their unique developmental needs influence their information needs and information behavior (Agosto \& Hughes-Hassell, 2006).

This literature review explores the Everyday Life Information-Seeking needs of adolescents. Adolescents are at a unique stage in their development and have needs that distinguish them from both younger children and adults. This review first defines Everyday Life Information-Seeking and adolescence. It then explores arguments that ELIS needs grow out of developmental needs. It describes several typologies of adolescents' ELIS needs. Finally, it examines the ELIS needs of specific adolescent populations.

\section{Everyday Life Information-Seeking}

Everyday Life Information-Seeking (ELIS) "refers to the acquisition of various informational (both cognitive and expressive) elements which people employ to orient themselves in daily life or to solve problems not directly connected with the performance of occupational tasks" (Savolainen, 1995, pp. 266-267). In the case of adolescents, this refers to daily life tasks or problems that extend beyond the realm of their school or work experiences. Savolainen notes that ELIS does not exclude occupational tasks; rather, it includes both occupational tasks and the many information needs and practices that are not encompassed in that sphere. Savolainen proposed and empirically tested a research framework for exploring ELIS practices, including how individuals' information-seeking is affected by their way of life ("the order of things," or the priority they place on everyday tasks) and their mastery of life ("keeping things in order," or the way they ensure that their everyday tasks are aligned with the priority they place on them). These two elements interact with an individual's values, attitudes, and interests, capital (material, social, and cultural), and current life situation (state of health, availability of time, etc.) to shape how they seek information.

The current literature review focuses on the ELI needs of adolescents rather than their ELIS practices; the most useful element of ELIS for this purpose is the distinction between the seeking of orienting information and the seeking of practical information (Savolainen, 1995). Orienting information is concerned with current events; it is not so much sought as it is monitored. Seeking orienting information may include passive monitoring of one's personal environment and of the media. This passive monitoring may bring to one's attention information that then spurs systematic investigation. For example, if one is planning an international trip and hears a news story about social upheaval in the travel destination in the news, this may prompt a call to a travel agency to investigate the situation further. Seeking of orienting information involves habitual information consumption such as viewing television, reading newspapers or magazines, and monitoring digital media including social media feeds, email newsletters, RSS feeds, and favorite websites. The seeking of practical information refers to seeking information to solve a specific problem, assist with a specific project, or meet a specific need. Most studies of information need look at this kind of information seeking, including most of the studies reviewed in this literature review. 
It is important to note that while Savolainen (1995) developed the ELIS framework, this is not the only framework used in studies of adolescents' ELI needs. Other frameworks used include Dervin's sense-making theory (used in Fisher, Marcoux, Meyers, \& Landry, 2007; Meyers, Fisher, \& Marcoux, 2007, 2009; Shenton \& Dixon, 2003, 2005), Chatman's normative behavior (used in Fisher et al., 2007; Meyers et al., 2007, 2009), and Fischer's information grounds (used in Fisher et al., 2007; Meyers et al., 2007, 2009).

\section{Adolescence}

Adolescence is a developmental stage of life with no commonly agreed upon definition. In its report, Developing Adolescents: A Reference for Professionals (2002), the American Psychological Association limits its discussion to young people ages 10 to 18. It is not so much an age range that defines adolescence, however, as a set of developmental characteristics and tasks. Developing Adolescents describes adolescents in terms of their physical, cognitive, emotional, social, and behavioral development. In terms of physical development, adolescents experience puberty and sexual development; they also demonstrate a growing concern with their own physical appearance and body image. Their cognitive development includes both growth in their reasoning abilities, demonstrated by increased interest and growing ability in argument and critical thinking, and moral development, as they identify their own moral values and ethical perspectives. As part of their emotional development, adolescents develop a sense of their own identity, struggle with building self-esteem, and learn to manage their own emotions and consider the emotional perspectives of others. With respect to emotional development, they increasingly focus on peer relationships including dating and sexual behaviors, becoming more independent of their families. Their social development is influenced by their school, work, and community environments, as well as the media. Finally, with respect to behavioral development, engagement in risk-taking behaviors increases in adolescence. It is important to recognize that most of the characteristics described in the research on which the Developing Adolescents report is based focuses on white, middle class, American adolescents; as such, it might not be generalizable to all adolescents. Furthermore, each adolescent's developmental path will proceed at a different pace and include individual struggles. Membership in a particular group, along lines such as gender, sexuality, disability status, and ethnic identity may influence this developmental path, especially the identity development component of it.

The developmental characteristics identified in the Developing Adolescents report are reflected in Havighurst's Developmental Tasks of Adolescence (Havighurst, 1948). Havighurst's tasks are sometimes referenced in discussion of adolescents' ELI needs (Agosto \& HughesHassell, 2005, 2006; Hughes-Hassell \& Agosto, 2007). These tasks include:

1. Adjusting to a new physical sense of self

2. Adjusting to new intellectual abilities

3. Adjusting to increased cognitive demands at school

4. Expanding verbal skills

5. Developing a personal sense of identity

6. Establishing adult vocational goals

7. Establishing emotional and psychological independence from his or her parents

8. Developing stable and productive peer relationships

9. Learning to manage his or her sexuality

10. Adopting a personal value system 
11. Developing increased impulse control and behavioral maturity (Agosto \& HughesHassell, 2006)

For the purposes of this literature review, studies that consider the needs of youth within the age range of 10 to 18 or that use a developmental perspective reflecting the characteristics identified in Developing Adolescents or Havighurst's developmental tasks will be included. Some such studies may encompass younger individuals, such as young tweens (ages 9 - 13), or older individuals, such as emerging adults (ages $15-23$ ). So long as the study has a developmental perspective within the scope of this literature review, it will be included.

\section{ELIS as a Function of Developmental Needs}

Adolescents' developmental needs drive their everyday life information needs, according to Agosto and Hughes-Hassell (2005, 2006; Hughes-Hassell \& Agosto, 2007). Drawing on Savolainen's ELIS framework, Agosto and Hughes-Hassell worked with twenty-seven Philadelphia young adults, aged 14 to 17 years, to create a model of the everyday life information needs of urban teenagers. The participants were volunteers but received a modest compensation. Twenty-five of them were African American, one was Asian-American, and one Caucasian; all were either members of the Free Library of Philadelphia's Teen Leadership Program or participants in the Boys and Girls Clubs of Philadelphia after school programs. Using surveys, written activity logs, audio journals, photographic tours, and group interviews, Agosto and Hughes-Hassell developed and, in conjunction with participants, revised a typology of the people teens consulted for information, the information sources they used, and their information needs. Details on this typology will be discussed in the next section.

Agosto and Hughes-Hassell (2005, 2006; Hughes-Hassell \& Agosto, 2007) connected their findings with Havighurst's (1948) developmental tasks, suggesting that his list "could explain some of the developmental functions that some of the participants' information needs topics supported" (2006, p. 1399). Not all of these information needs topics were addressed by one of Havighurst's tasks, however, so Agosto and Hughes-Hassell propose twelve additional developmental tasks of adolescence:

a. Understanding and negotiating the social world

b. Seeking emotional health and security

c. Establishing relationships with adults other than parents/guardians

d. Developing a sense of civic duty

e. Establishing a cultural identity

f. Questioning how the world works

g. Developing physical self-sufficiency

h. Seeking physical safety and security

i. Expressing artistic preferences

j. Expressing aesthetic preferences

$\mathrm{k}$. Understanding the physical world

1. Learning to recognize and accept his or her sexuality (Agosto \& Hughes-Hassell, 2006)

Agosto and Hughes-Hassell argue that "the essence of urban teens' ELIS is the gathering and processing of information to facilitate the multifaceted teen-to-adult maturation process" (2006, p. 1401). ELIS doesn't exist independently of teens' developmental process, but rather grows out of it. Agosto and Hughes-Hassell suggest that unlike research on adult ELIS, which focuses on topics such as health issues, consumer issues, housing, and hobbies as individual 
needs, these topics arise in teens' ELIS as natural outgrowths of their developmental needs. ELIS helps teenagers explore their own identities, the world around them, and their position in that world, "as well as helping them to understand themselves now and to understand who they aspire to be in the future" (2006, p. 1401).

Meyers, Fisher, and Marcoux also connect ELIS with developmental needs (Fisher et al., 2007; 2007, 2009). In a study designed to explore why tweens (youth aged $9-13$ years) turn to other people as sources of everyday information, they used focus groups and individual interviews to learn about the ELIS of sixteen tweens whose families were affiliated with a major research university, five tweens who were members of an urban church ministry, and thirteen students at a local suburban elementary school. Incorporating Vygotsky's theory of the social formation of the mind, Meyers and colleagues identify two key developmental processes at work in early adolescence: "socialization (how they come to adopt social norms and processes of relating to others) and individuation (how they develop a unique identity among peers)" (2009, p. 336). Meyers and colleagues argue that both of these developmental processes require tweens to engage with everyday life information from both formal and informal sources, influencing "what is important to know as well as how it is sought and known" (2009, p. 307).

\section{Typologies of Adolescents' ELIS Needs}

A number of studies have examined adolescents' ELIS needs and constructed typologies of these needs (Agosto \& Hughes-Hassell, 2005, 2006; Hughes-Hassell \& Agosto, 2007; Latrobe \& Havener, 1997; Minudri, 1974; Poston-Anderson \& Edwards, 1993; Shenton \& Dixon, 2003). While each study resulted in its own typology, there is overlap in the types of information needs identified.

Regina Minudri (1974), a public librarian and specialist in serving young adults and students, presented a typology of young adults' information needs at a small, invitational conference on user needs sponsored by the National Commission on Libraries and Information Science. Minudri prefers not to define the age range of young adults, but tends to use the age range $10-20$; her typology of needs does not appear to be empirically grounded but instead based in her own experience serving this population. The needs she identifies include:

1. School \& curriculum needs

2. Recreational needs

3. Personal development needs (goal-setting, self-actualization)

4. Vocational and career information needs

5. Accomplishment skills and information needs (refers to skill-building hobbies such as mechanics, sewing, sports, crafts - distinct from recreational needs, which tend more toward entertainment)

Latrobe and Havener (1997) studied 18 high school honors students and identified the following needs:

1. Course-related

2. Current lifestyles

3. Future plans

4. Relationships with others

5. Health

6. General information 
Shenton and Dixon (2003) define information need as "the desire or necessity to acquire intellectual material required by a person to ease, resolve, or otherwise address a situation arising in his or her life" (p. 37). Working with 188 children aged $4-18$, they used focus groups and individual interviews, asking informants to think of a time when they "needed help making a decision" and "were worried about something and needed to learn about it," then asked them "to describe the action they had taken in response" (p. 37). They coded their results inductively using constant comparison. They identified thirteen needs:
1. Advice (assistance in making decisions, choosing between possible actions)
2. Response to problems (overcoming a barrier in a desired course of action)
3. Personal information (basic information about health, the environment, times, dates)
4. Affective support (reassurance and sympathy)
5. Empathetic understanding
6. Support for skill development
7. School-related subject information
8. Interest-driven information
9. Consumer information
10. Self-development information (might include school or career)
11. Prepatory information (preparing for an upcoming challenge)
12. Reinterpretations and supplementations of information (further explanation of information already possessed)
13. Verificational information (confirmation or denial of information already possessed)

It is important to note that Shenton and Dixon do not distinguish between needs identified by adolescents and needs identified by younger children.

In their study, introduced in the previous section, Agosto and Hughes-Hassell (2005, 2006; Hughes-Hassell and Agosto, 2007) identified 28 topics encompassing the ELI needs of urban teenagers:

1. Daily life routine

2. Social activities

3. Creative performance

4. Academics

5. Personal finances

6. Current events

7. Goods and services

8. Emotional health

9. Friend/peer/romantic relationships

10. Popular culture

11. Familial relationships

12. Fashion

13. College

14. Health
15. Physical Safety

16. Self-image

17. Job responsibilities

18. Social/legal norms

19. Philosophical concerns

20. Creative consumption

21. Career

22. School culture

23. Sexual safety

24. Sexual identity

25. Religious practice

26. Civic duty

27. Heritage/cultural identity

28. Self-actualization

Conidering these needs in combination with Havighurst's developmental tasks and the developmental tasks they generated to expand upon Havighurst's list, Agosto and HughesHassell created a theoretical model that identified seven areas of teen development, or "selves." Each developmental task and information need is associated with one of these selves: 
1. Social self: understanding how you fit in the human social world

2. Emotional self: understanding your inner world of feelings and emotions

3. Reflective self: developing a sense of identity, values, and critical questioning

4. Physical self: understanding one's body and health, seeking physical safety

5. Creative self: fulfilling aesthetic needs through the consumption or production of art and culture

6. Cognitive self: processing and navigating the physical world intellectually

7. Sexual self: managing your sexuality, understanding and accepting your sexual identity

Agosto and Hughes-Hassell focused their work on urban teens because previous studies of adolescents' ELIS needs had examined predominantly white, middle-class populations. They found that the needs identified in earlier studies were consistent with the theoretical model they built, concluding that this finding suggests that "teenagers have similar information needs across socioeconomic, ethnic, cultural, and geographic boundaries" (Hughes-Hassell and Agosto, 2007, p. 55).

\section{ELIS Needs of Specific Adolescent Populations}

While Agosto and Hughes-Hassell conclude that teenagers share a similar set of information needs regardless of their socioeconomic status, ethnicity, membership in a particular culture, or geographic location, some scholars have studied the needs of particular adolescent populations.

\section{Homeless Youth}

Markwei and Rasmussen (2015) investigated the ELIS behavior of homeless youth in Accra, Ghana. Using snowball sampling, they recruited 41 homeless youth, aged 15 to 18 , to participate in a qualitative study. They collected data using field observations, in-depth interviews, and an adaptation of the critical incident technique. They identified 10 categories of needs:
1. Money
6. Security
2. Shelter
3. Employment
7. Respect
4. Education
8. Justice
5. Skills development
9. Food
10. Fair wages

Unlike other studies of adolescents' ELIS needs, which connect those needs to developmental theories such as Havighurst's developmental tasks or Vygotsky's social formation of the mind, Markwei and Rasmussen connect their findings to Maslow's hierarchy of needs (1943), which include physiological need, safety need, belonging need, esteem need, and selfactualization need. Markwei and Rasmussen identify food as a physiological need, money, employment, fair wages, shelter, security, justice, and health as safety needs, respect as an esteem need, and education and skills development as self-actualization needs. While participants expressed their needs as complaints rather than information needs, Markwei and Rasmussen concluded that to meet these needs, participants do, in fact, require information and advice. While the participants in this study are focused on meeting basic needs, some of their 
needs do overlap with the needs identified in other studies, such as education and skills development.

\section{Upper-Income Teens in a Highly Technological Environment}

Inspired by Agosto and Hughes-Hassell's work, Franklin (2013a, 2013b) designed a study that would ask similar questions of a different population and in a different setting. Franklin investigated the "information behavior of upper-income students attending a newly constructed, highly technological Midwestern high school" (2013a, p. 53). She purposively selected a Midwestern high school, choosing it because its students have the opportunity to use not only technology provided by the school, but their own technology as well such as smart phones. This is, according to Franklin, unusual in the school district where these students live. Franklin performed a single-site case study, working with two school librarians and 42 student participants. She gathered data via nonparticipant observations, interviews of the school librarians, focus groups with the students, online student surveys, and documentation. In the focus groups, she worked with 27 students: 15 males and 12 females, aged 14 through 19. All students were volunteer participants. Documentation included news articles from a variety of sources, school paperwork such as bell schedules, photographs generated for the study, and the school library's online presence including the website, LibGuides, and social media.

Franklin found that both school librarians and suburban teens struggled to identify specific everyday life information needs. When pressed, both groups mentioned academics, social activities, cars, gaming, and travel. School librarians identified daily life routine, fashion, college, current events, popular culture, and social/legal norms as needs they witnessed in their students. Students added creative consumption: searching for media to use in their own creative, "mash-up style" projects. Franklin notes that gaming, cars, and travel are not included in Agosto and HughesHassell's typology. In addition, the suburban teens expressed very specific academic needs such as test schedules, exam dates and locations, and grades, which they used their own cell phones and smart phones to check online. These needs were more focused on specific, measurable academic achievement than the needs expressed by the participants in Agosto and Hughes-Hassell's study, who referred to more general needs such as assistance with assignments.

\section{"Queer" Youth Coming Out}

Mehra and Braquet (2007) investigate the information seeking of "queer" youth during the coming out process. They use the word "queer" "to include diverse expressions and manifestations that are not heterosexual and include gay, lesbian, bisexual, transgender, and questioning youth," considering it the most inclusive term available to represent sexual minorities, and use the word "queer" in quotation marks "to recognize the history of abuse, ridicule, discrimination, and violence projected against 'queer' people” (p. 96). Mehra and Braquet use in-depth narrative interviews and informal discussions to learn about the coming out experiences of twenty-one "queer" participants from a representative city in the Southern United States. The participants include "two lesbians, twelve gay men, six bisexuals (four women and two men) and one heterosexual transgender (female-to-male) individual" (p. 106). It is important to note that these were the identifications the participants themselves used. The interviews included questions about participants' coming out experiences, the types of information sources they sought and their roles in the coming out process, their information-seeking behaviors and how they related to thoughts, feelings, and actions, and ideal information support services they sought during the different phases of coming out. Mehra and Braquet used grounded theory to analyze the data, using open, axial, and selective coding. 
For the purposes of this literature review, the most relevant findings are those about the role of information sources participants sought throughout their coming out process. These roles can be considered indicative of "queer" youths' information needs throughout this process. Mehra and Braquet divide these needs/roles among five phases of coming out: "self-recognition of being different; sharing with other 'queer' people in order to become part of a 'queer' social network and community; telling close friends, relatives, and coworkers; development of a positive self-identification; integration into all parts of one's life and acceptance of being 'queer'" (p. 97). During the self-recognition phase, needs included developing an understanding of sexuality in general, what it means to be "queer," the types of experiences participants could expect to have during the coming out process, and examples of individuals who were openly "queer." During the phase of sharing with other "queer" people, needs included finding information about local "queer" people and groups in order to become a member of the "queer" community. During the phase of disclosing queerness to family and friends, needs focused on providing institutional and authoritative legitimacy to "queer" issues and presenting "simple, clear, and easy to understand explanations and descriptions" (p. 112) that friends and family could understand. During the positive self-identification phase, participants indicated a need for information about how to achieve political, legal, civil, social and individual equality and fairness. Finally, during the integration and acceptance phase, information needs emphasized connecting "queer" interests with all aspects of everyday life including travel, career, advocacy, and education concerns.

While the needs Mehra and Braquet identify fit well into Agosto and Hughes-Hassell's model, addressing the social, reflective, and sexual selves, the specific needs they identify are unique not only to "queer" individuals, but to the coming out process itself. This provides an example of how apparently universal needs might manifest in specific ways; both practitioners and researchers should take into consideration the types of information needs that might apply to a particular population of adolescents.

\section{Intellectual Disabilities}

Hanson-Baldauf $(2012 ; 2013)$ studied the ELIS needs, practices, and challenges of emerging adults with intellectual and developmental disabilities (I/DD). Hanson-Baldauf used purposive and convenience sampling to recruit four participants, two males and two females. All participants were familiar to her from her own participation in the Special Olympics community as a sibling of an individual with I/DD. She collected data using semi-structured interviews with participants, their family members, and their teachers, participant and non-participant observations at school, at home, and in the community, the photovoice method, and document collection and review.

Hanson-Baldauf categorized the identified information needs into two categories: expressed information needs, needs either stated or demonstrated by participants themselves, and ascribed information needs, needs inferred and reported by others (such as family members or teachers). She identified twenty-nine areas of ELIS needs:
1. Academic endeavors
2. Communication skills
7. Curiosities, interests, hobbies, and
3. Community access pastimes
4. Consumer information
8. Emotional health/coping skills
5. Correspondence skills
9. Employment
6. Creative endeavors/expressions
10. Financial literacy/money management 11. Future planning 
12. Identity

13. Independent life skills

14. Personal safety

15. Health and development

16. Relations

17. Responsibilities

18. Schedule development/maintenance

19. Self-care skills

20. Self-determination/self-advocacy
21. Sexual literacy

22. Social life /recreational activities

23. Social skills

24. Spirituality/religion

25. Sports/physical activities

26. Technology skills

27. Transliteracy skills

28. Volunteering/service to others

29. World, national, community awareness

Hanson-Baldauf concludes that the ELIS needs of emerging adults with I/DD are very similar to the needs of neurotypical adolescents as identified in other studies such as Agosto and Hughes-Hassell's. Hanson-Baldauf proposes a model of ELIS for emerging adults with I/DD that integrates Agosto and Hughes-Hassell's model, adding components related to the way that ELIS affects quality of life for individuals with I/DD. These components include, in addition to Agosto and Hughes-Hassell's seven selves, a set of assets directed toward facilitating self-actualization including an enabling environment, knowledge, skills, and social capital, a set of positive affirmations that affirm the individual's capacity for self-determination, and a set of domains that influence quality of life for individuals with I/DD including rights, interpersonal relations, social inclusion, emotional well-being, physical well-being, material well-being, personal development, and self-determination. Hanson-Baldauf's model acknowledges the potential universality of Agosto and Hughes-Hassell's model while expanding it to describe the unique needs of a specific population.

\section{Conclusion}

Everyday Life Information-Seeking is a field of study that allows us to consider adolescents not only in their identities as students, but as individuals transitioning from childhood to adulthood. The process of seeking information is one that facilitates adolescents' growth and maturation and helps them explore themselves, the world, and their place in it. While many researchers have identified specific information needs of adolescents, there do seem to be broad categories of need that apply across socioeconomic, ethnic, cultural, and geographic boundaries. In spite of this, some youth populations, such as "queer" youth, individuals with I/DD, and homeless youth have specific needs that librarians and researchers should keep in mind as they plan services and research. 


\section{References}

Agosto, D. E., \& Hughes-Hassell, S. (2005). People, places, and questions: An investigation of the everyday life information-seeking behaviors of urban young adults. Library \& Information Science Research, 27(2), 141-163. http://doi.org/10.1016/j.lisr.2005.01.002

Agosto, D. E., \& Hughes-Hassell, S. (2006). Toward a model of the everyday life information needs of urban teenagers, part 1: Theoretical model. Journal of the American Society for Information Science and Technology, 57(10), 1394-1403.

http://doi.org/10.1002/asi.20451

Bernier, A. (2007). Introduction: "Not Broken by Someone Else's Schedule: On Joy and Young Adult Information Seeking. In M. K. Chelton \& C. Cool (Eds.), Youth InformationSeeking II: Context, Theories, Models, and Issues (pp. xiii-xxviii). Lanham, Md.: Scarecrow Press.

Developing Adolescents: A Reference for Professionals. (2002). American Psychological Association.

Fisher, K. E., Marcoux, E., Meyers, E., \& Landry, C. F. (2007). Tweens and everyday life information behavior: Preliminary findings from Seattle. Youth Information-Seeking Behavior II: Theories, Models and Issues, 1-26.

Franklin, L. (2013a). Everyday Life Information-Seeking Practices of Upper-Income High School Students. In M. J. Dow (Ed.), School Libraries Matter: Views from the Research (pp. 51-64). ABC-CLIO.

Franklin, L. (2013b, July 10). Everyday Life Information Seeking (ELIS) Practices of Suburban Teens in A Highly Technological School Library: A Case Study (Thesis). Retrieved from https://esirc.emporia.edu/handle/123456789/3252 
Hanson-Baldauf, D. (2012). Everyday Life Information in Support of Enhanced Quality of Life for Young Adults with Intellectual Disabilities. The Information Behavior of a New Generation: Children and Teens in the 21st Century, 167.

Hanson-Baldauf, D. J. (2013). Exploring the Everyday Life Information Needs, Practices, and Challenges of Emerging Adults with Intellectual Disabilities (Doctoral Dissertation). University of North Carolina-Chapel Hill, Chapel Hill, NC. Retrieved from https://cdr.lib.unc.edu/record/uuid:8d6d0921-9912-474b-979d-7c7e10c7a7cb

Havighurst, R. J. (1948). Developmental tasks and education (Vol. iii). Chicago, IL, US: University of Chicago Press.

Hughes-Hassell, S., \& Agosto, D. E. (2007). Modeling the everyday life information needs of urban teenagers. Youth Information Seeking Behaviors: Context, Theories, Models, and Issues II, 27-61.

Latrobe, K., \& Havener, W. M. (1997). The Information-Seeking Behavior of High School Honors Students: An Exploratory Study. Journal of Youth Services in Libraries, 10(2), $188-200$.

Markwei, E., \& Rasmussen, E. (2015). Everyday Life Information-Seeking Behavior of Marginalized Youth: A Qualitative Study of Urban Homeless Youth in Ghana. International Information \& Library Review, 47(1-2), 11-29. http://doi.org/10.1080/10572317.2015.1039425

Maslow, H. A. (1943). A theory of human motivation. Psychological Review, 50(4), 370-396. http://doi.org/10.1037/h0054346 
Mehra, B., \& Braquet, D. (2007). Process of information seeking during “queer” youth comingout experiences. Youth Information-Seeking Behavior II: Contexts, Theories, Models, and Issues, 93-131.

Meyers, E. M., Fisher, K. E., \& Marcoux, E. (2007). Studying the everyday information behavior of tweens: Notes from the field. Library \& Information Science Research, 29(3), 310331. http://doi.org/10.1016/j.lisr.2007.04.011

Meyers, E. M., Fisher, K. E., \& Marcoux, E. (2009). Making Sense of an Information World: The Everyday-Life Information Behavior of Preteens. The Library Quarterly: Information, Community, Policy, 79(3), 301-341. http://doi.org/10.1086/599125

Minudri, R. (1974). Library and Information Services for Young Adults and Students. In M. J. | Bates \& C. A. | Cuadra (Eds.), Library and information service needs of the Nation: proceedings of a Conference on the Needs of Occupational, Ethnic, and Other Groups in the United States. (pp. 155-161). Washington: Government Printing Office.

Poston-Anderson, B., \& Edwards, S. (1993). The Role of Information in Helping Adolescent Girls with Their Life Concerns. School Library Media Quarterly, 22(1), 25-30.

Savolainen, R. (1995). Everyday life information seeking: Approaching information seeking in the context of "way of life." Library \& Information Science Research, 17(3), 259-294. http://doi.org/10.1016/0740-8188(95)90048-9

Shenton, A. K., \& Dixon, P. (2003). Just what do they want? What do they need? A study of the informational needs of children. Children and Libraries, 1(2), 36-42.

Shenton, A. K., \& Dixon, P. (2005). Information needs: Learning more about what kids want, need, and expect from research. Children and Libraries, 3(2), 20-28. 
Young Adult Library Services Association (YALSA). (2011). YALSA National Research

Agenda. Retrieved February 4, 2016, from

http://www.ala.org/yalsa/guidelines/research/researchagenda\#area3 